\title{
Measuring Target Effect of Proposed Disease-Modifying Therapies in Alzheimer's Disease
}

\author{
Randall J. Bateman* and William E. Klunk ${ }^{\dagger}$ \\ *Department of Neurology, Washington University School of Medicine, St. Louis, Missouri 63110; and ${ }^{\dagger}$ Department of \\ Psychiatry, School of Medicine, University of Pittsburgh, Pittsburgh, Pennsylvania 15213
}

\begin{abstract}
Summary: Alzheimer's disease (AD) is the most common cause of dementia and is an increasing public health problem. Because of the severity and increasing prevalence of the disease in the population, it is urgent that better treatments be developed. Active research efforts over the past several decades have produced a vast knowledge base regarding $\mathrm{AD}$ natural history, pathology, and key biological mediators involved in pathogenesis. As knowledge of the biomolecular mechanisms of $\mathrm{AD}$ has increased over the past several decades, there has been a growing consensus on the pathophysiology of the dis-
\end{abstract}

ease. These scientific advancements have led to proposals for disease-modifying therapeutic interventions that promise to significantly alter the course of AD. The translation from preclinical models to human studies requires therapeutic biomarkers to increase the likelihood of success. This review covers the current methods and technologies used in the therapeutic translation of proposed disease-modifying therapies for AD. Key Words: Alzheimer's disease, Alzheimer, treatment, biomarker, amyloid, amyloid- $\beta, \mathrm{CSF}$, cerebrospinal fluid, therapeutic, kinetics, production, clearance, PET, PiB.

\section{INTRODUCTION}

Alzheimer's disease (AD) is the most common cause of dementia and is an increasing public health problem. It is currently estimated to afflict 5 million people in the United States, with an expected increase to 13 million by the year 2050. ${ }^{1}$ Alzheimer's disease leads to loss of memory, cognitive function, and ultimately independence, and so it takes a heavy personal and financial toll on the patient and the family. Because of the severity and increasing prevalence of the disease in the population, it is urgent that better treatments be developed.

Active research efforts over the past several decades have produced a vast knowledge base regarding $\mathrm{AD}$ natural history, pathology, and key biological mediators involved in pathogenesis. As knowledge of the biomolecular mechanisms of $\mathrm{AD}$ has increased over the past several decades, there has been a growing consensus on the pathophysiology of the disease. These scientific advancements have led to proposals for disease-modifying

Address correspondence and reprint requests to: Randall J. Bateman, MD, Department of Neurology, Washington University School of Medicine, 660 S. Euclid, Box 8111, St. Louis, MO 63110.E-mail: batemanr@ wustl.edu. therapeutic interventions, which promise to significantly alter the course of AD.

\section{AMYLOID HYPOTHESIS}

The most widely accepted hypothesis for the etiologic cause of $\mathrm{AD}$ is the amyloid hypothesis. ${ }^{2}$ This scientific theory, based on multiple lines of evidence, proposes that amyloid- $\beta(\mathrm{A} \beta)$ in one or more toxic forms causes a cascade of events that are toxic to neurons and cause progressive dementia of the Alzheimer's type. Some of the earliest evidence for the amyloid hypothesis came when $\mathrm{A} \beta$ was sequenced from the extracellular deposits in amyloid plaques and cerebral amyloid angiopathy. ${ }^{3}$

Although the precise pathogenic form of $A \beta$ is not yet known, it is clear that alteration of $\mathrm{A} \beta$ metabolism is necessary and sufficient to cause certain autosomal dominant forms of $\mathrm{AD}^{4-6}$ Mutations in one of three genes have been identified in familial AD and affect the production, ratio of species, or biochemical properties of A $\beta$. Mutations in either presenilin 1 or presenilin 2, which are components of $\gamma$-secretase, lead to alterations in the production of the $A \beta_{42} / A \beta_{40}$ ratio. ${ }^{6}$ Mutations in the amyloid precursor protein gene $(A P P)^{5}$ can affect the production of $A \beta$ or its propensity to aggregate. Individuals with trisomy 21 (with an extra copy of $A P P$ ) invari- 
ably develop $\mathrm{A} \beta$ deposits by their 40 s, and progressive AD. An extra copy of the APP locus is sufficient to cause $\mathrm{AD}$ in individuals without complete trisomy $21 .^{7}$ These observations provide evidence in humans that increased dosage or misprocessing of $A \beta$ is sufficient to cause AD. Autosomal dominant AD mutations have been used in creating animal models of $\mathrm{AD}$ that recapitulate much of the amyloid pathology seen in the human form of the disease. ${ }^{8,9}$ Models using multiple transgenes (including human tau) incorporate tau pathology and progressive neurobehavioral decline. ${ }^{10-13}$

\section{Toxic species of $\mathbf{A} \boldsymbol{\beta}$}

The exact species of $A \beta$ that contributes to neurodegeneration and progressive dementia is still not clearly defined and is discussed elsewhere. ${ }^{14-19}$ However, it is likely that several forms of $\mathrm{A} \beta$ contribute to the pathophysiology of $\mathrm{AD}$, because $\mathrm{A} \beta$ plaques show clear neuritic dystrophy and surrounding inflammation, ${ }^{20-22}$ and various oligomeric species interfere with long-term potentiation. $^{23,24}$ An important concept is that various forms of $A \beta$ are in dynamic equilibrium, and interconversion between less toxic and more toxic forms is likely a continuous phenomenon. The insoluble pool of $\mathrm{A} \beta$ is typically 100 -fold larger than the soluble pool, so any changes in the concentration of $\mathrm{A} \beta$ monomers or oligomers may be readily buffered by equilibrium with the insoluble pool. Given that the ultimate target of $\mathrm{AD}$ treatment is the toxic form of $\mathrm{A} \beta$, a way to measure the amyloid plaques and oligomer species in the brains of humans is of critical importance. In 2004, collaborating groups from Uppsala and Pittsburgh first reported a breakthrough of imaging amyloid in living humans using positron emission tomography (PET) and the radiotracer that has come to be known as Pittsburgh Compound B or $\mathrm{PiB}^{25}$ This imaging technique has been validated in human $\mathrm{AD}$ brain and has received extensive interest from academic centers, which are now using this imaging for advancing the understanding of $\mathrm{AD}{ }^{26,27}$

\section{$A \beta$ as a therapeutic target}

Because of the central role of $\mathrm{A} \beta$ in $\mathrm{AD}$, intensive research has focused on the physiology and pathophysiology of $A \beta$ in cell culture systems, animal models, and humans. Therapeutic developments aimed at modifying disease progression have primarily targeted $A \beta$ in one of four ways: decreased production, increased degradation, increased clearance, or inhibiting aggregation or toxicity to neurons in the central nervous system (CNS). Many of the proposed pathways for disease modification in $\mathrm{AD}$ are described in detail elsewhere in this issue. In addition, there are excellent reviews by others that focus on proposed treatments. ${ }^{28,29}$ The present review focuses on methods to measure responses to proposed disease-modifying therapies that target $\mathrm{A} \beta$. Principles discussed here may be applied to other targets in the CNS.

\section{Production and clearance of $\mathbf{A} \boldsymbol{\beta}$}

Within the CNS, $A \beta$ is produced mostly by neurons as a normal physiologic process. ${ }^{30}$ Recent evidence indicates production of $A \beta$ is related to neuronal activity. ${ }^{31-33} \mathrm{~A} \beta$ is cut from the transmembrane protein APP by $\beta$-secretase and then $\gamma$-secretase enzymes and is released into the extracellular space. Extracellular $A \beta$ is normally degraded or cleared out of the CNS, maintaining a homeostatic balance. In $\mathrm{AD}$, however, $\mathrm{A} \beta$ levels in the brain increase 100- to 1000 -fold normal levels. Increased production or decreased clearance may cause this massive increase in $A \beta$, but the contribution of each in $\mathrm{AD}$ pathogenesis is still not known. ${ }^{34,35}$

In autosomal dominant $\mathrm{AD}$, mutations result in $\mathrm{A} \beta$ dysregulation and subsequent $\mathrm{AD}$ pathology similar to that seen in the more common late-onset AD. ${ }^{36}$ However, the regional distribution of amyloid early in the course of some forms of autosomal dominant $\mathrm{AD}$ is often atypical. ${ }^{37}$ Several animal models of $\mathrm{A} \beta$ deposition are based on the human AD mutations, and the pathology observed in these transgenic mice appears to be due primarily to $\mathrm{A} \beta$ deposition, including neuritic plaques, cerebral amyloid angiopathy, microglial activation, astrocytosis, evidence of oxidative damage, and changes in neuronal cytoskeletal proteins. ${ }^{38}$ A study of $\mathrm{A} \beta$ clearance in a mouse model of $\mathrm{AD}$ demonstrated that the elimination half-life of $A \beta$ in the brain interstitial fluid is $2 \mathrm{~h}$ in mice without AD pathology and $4 \mathrm{~h}$ in mice with AD pathology. ${ }^{39}$ The altered CNS $A \beta$ clearance rate was associated with the presence of amyloid plaques.

The levels of $A \beta$ in the CSF reflect the balance of production in the extracellular space of the brain and clearance from the brain and CSF compartment. In diagnostic studies of $\mathrm{AD}$, the level of CSF $\mathrm{A} \beta_{42}$ is significantly decreased in $A D$ but the level of CSF $A \beta_{40}$ is unchanged. ${ }^{40-42} \operatorname{CSF} \mathrm{A} \beta$ is transported to the venous blood via the arachnoid granulations. To a lesser degree, plasma $\mathrm{A} \beta_{40}$ and $\mathrm{A} \beta_{42}$ have been shown in some studies to increase with age and in early $\mathrm{AD}$; however, both may decrease with advancing $\mathrm{AD}$, suggesting that advanced $\mathrm{AD}$ may alter the clearance of $\mathrm{A} \beta$ from the brain to the blood in vivo. ${ }^{43}$

The relative contributions of CNS A $\beta$ clearance mechanisms in humans are not known. These mechanisms include breakdown within the CNS, transport from the brain to the blood directly (via the blood-brain barrier $[\mathrm{BBB}])$, and transport from the brain to the CSF and then to the blood. Understanding human CNS A $\beta$ production, transport, and clearance kinetics by determining the production and clearance rates of $\mathrm{A} \beta$ in the CNS and in blood is likely to provide novel insights into $\mathrm{A} \beta$ physiology and potentially the pathophysiology that leads to AD. 


\section{Measurement of $\mathbf{A} \boldsymbol{\beta}$ production and clearance in humans}

To address critical questions regarding $\mathrm{A} \beta$ metabolism, a method was developed that measures $\mathrm{A} \beta$ fractional production rate and clearance rate in vivo in humans. Results indicate that by administering a stable isotope labeled amino acid $\left({ }^{13} \mathrm{C}_{6}\right.$-leucine $)$ and using high-resolution mass spectrometry, reproducible kinetics of $\mathrm{A} \beta$ production and clearance can be quantified in normal human research participants (FIG. 1). ${ }^{44}$ Using this protein stable isotope labeling kinetics (SILK) technique, it has been shown that $\mathrm{A} \beta$ has a rapid production and clearance rate of $\sim 8 \%$ per hour in normal control participants aged 20 to 50 years. ${ }^{45}$ Ongoing studies are investigating how these rates may be altered by aging or presence of $\mathrm{AD}$.

\section{A $\beta$ plaque formation}

The exact mechanism of $\mathrm{A} \beta$ deposition in plaques is not well understood. It is clear that an increase of the longer, 42 amino acid form of $\mathrm{A} \beta$ ultimately leads to plaque formation. ${ }^{46}$ However, basic questions such as whether plaques represent a central nidus of concentrated $\mathrm{A} \beta$ originating from a local cellular source that is diffusing outward or a convergence of extracellular $\mathrm{A} \beta$ condensing toward a central core remain unanswered. Two-photon microscopic studies in transgenic mice have provided some of the most revealing insights into the process of plaque formation in these mouse models, and perhaps in humans. Recent evidence has shown that plaques can form surprisingly rapidly, within $24 \mathrm{~h}$, in transgenic mice and that these plaques appear to quickly stabilize in size and do not grow further. ${ }^{47}$ This finding would seem to favor the notion that plaque formation results from a paroxysmal event, but the nature of that event is unknown.

In humans, plaque formation may be more complex. There are several histological types of plaques, and the relationship among the various forms is not clear. ${ }^{48}$ It is commonly believed that diffuse plaques (i.e., plaques lacking a dense central core) may be an early stage that later evolves into compact, cored plaques, but this has not been proven. Dystrophic neurites, swollen with hyperphosphorylated tau, rarely associate with diffuse plaques, but frequently interdigitate in and surround cored plaques, forming the so-called neuritic plaque. A halo of astrocytic-microglial response and neuritic and axonal dystrophy radiates from the plaque core, suggesting the existence of a gradient of a toxic, diffusible species, perhaps oligomeric $A \beta$ in equilibrium with the much more abundant (100-fold) fibrillar $\mathrm{A} \beta$ that composes the cored and neuritic plaque.

\section{Measurement of $\mathbf{A} \boldsymbol{\beta}$ plaques in humans}

Prior to the development of molecular probes that bind amyloid plaques, the only way for measurement of plaques was via biopsy or postmortem analysis of tissue. $\mathrm{PiB}, \mathrm{FDNNP}$, and other tracers have been developed to detect $A \beta$ deposits in plaques and cerebrovascular amyloid. PiB PET, the most well studied to date, demonstrates good correlation to pathological findings. ${ }^{49,50}$ Careful correlation of in vivo PiB retention with histology in autopsy samples from an AD patient who had been imaged with $\mathrm{PiB}$ prior to death showed that $\mathrm{PiB}$ binds to fibrillar $\mathrm{A} \beta$ (whether in diffuse-appearing or compact plaques or cerebrovascular amyloid), but not to tau in tangles. ${ }^{50} \mathrm{PiB}$ does not appear to detect Lewy bodies. ${ }^{51}$ Fleecy, amorphous deposits of $\mathrm{A} \beta$, composing the majority of cerebellar amyloid, also is not stained by PiB. ${ }^{50}$

\section{THERAPY IDENTIFICATION}

One can use advancements in measuring $\mathrm{A} \beta$ physiology in humans to measure effects of therapies that target $\mathrm{A} \beta$. Traditional drug discovery centers on a model of screening compounds for therapeutic target hits in a high-throughput system that is typically enzyme- or cellbased. Identification of these compounds eventually leads to testing of drugs in animal models of AD. These preclinical studies evaluate the effectiveness of the treatment in blocking or reversing the pathology, as well as behavioral performance. After preclinical validation in one model, more extensive validation is recommended, including testing in other models and at multiple doses. After toxicology studies are completed in animal models, the program may advance to first in-human studies. These phase I studies are typically done for toxicology purposes, to determine clinical side effects, as well as pharmacokinetics. In this translation from preclinical to clinical trials, evidence of a pharmacodynamic effect in humans is highly recommended. Phase II studies in patients with $\mathrm{AD}$ further test safety, pharmacokinetics, and pharmacodynamic effects. These translational steps from preclinical models to human studies are not incremental and represent a leap in therapeutic testing from nonhuman animal models to clinical studies.

\section{Preclinical versus clinical}

There are many differences between preclinical studies and clinical studies that may account for variable responses to the same dose of the therapy. The differences between animal models and humans may be categorized as follows:

1) Difference in species, which includes different background genetic variability, ${ }^{52}$ brain structure and function, differences in CNS cells including neurons and glia, groups of interacting proteins, and the dynamics of $\mathrm{A} \beta$.

2) Differences in the pathogenesis and pathology of AD. Animal models are most similar to the early- 

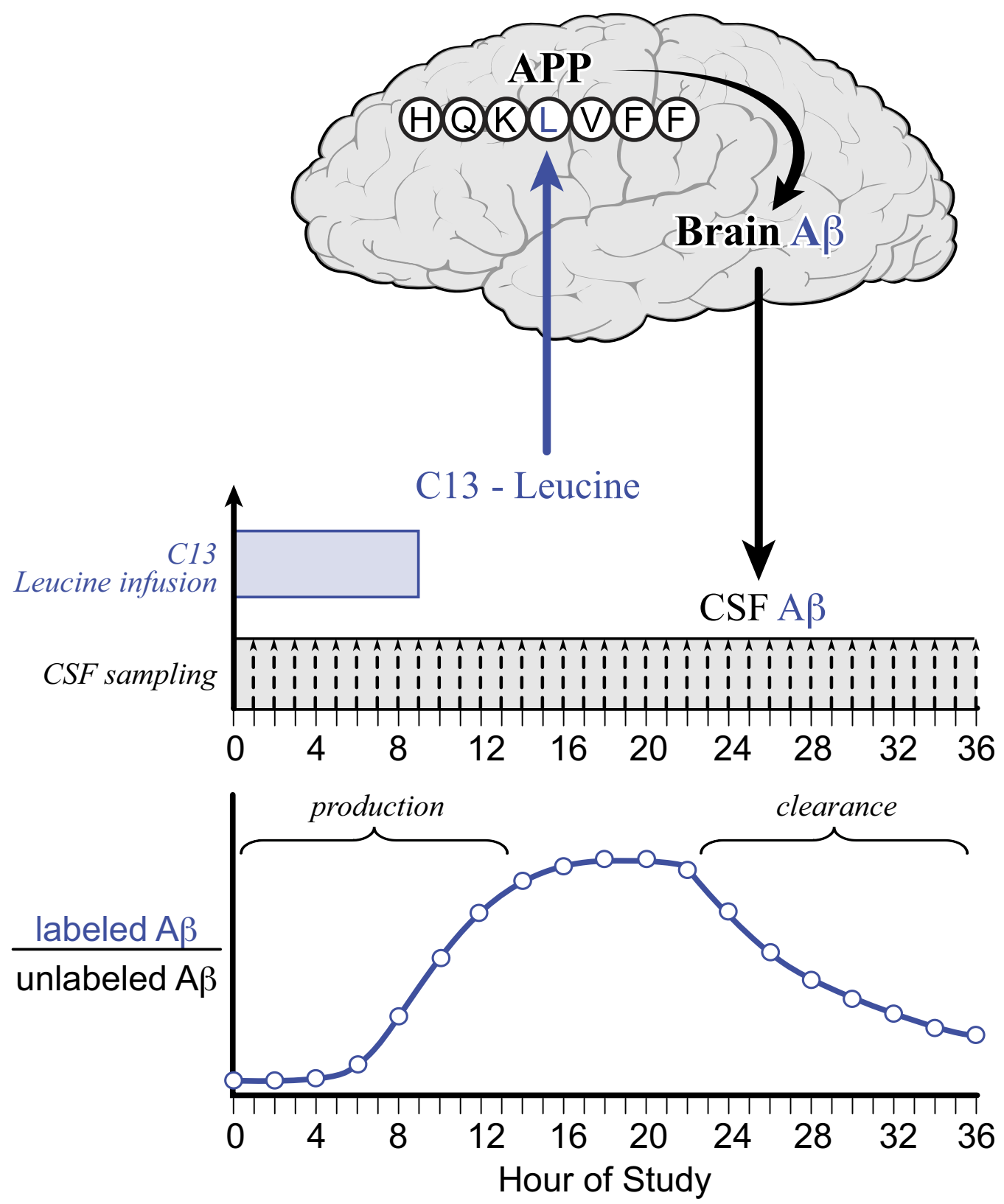

FIG. 1. Diagram of CNS protein stable isotope labeling kinetics (SILK). Top: Carbon-13 stable isotope label $\left({ }^{13} \mathrm{C}_{6}\right.$-leucine) is administered for $9 \mathrm{~h}$, to label newly synthesized proteins as labeled amino acids are incorporated into proteins during synthesis; the partial amino acid sequence of APP/A $\beta$ containing the labeled leucine (blue $L$, circled) is indicated. The A $\beta$ is generated from APP ( $\beta$ - and $\gamma$-secretase) to the extracellular space of the brain, which is in direct communication with the CSF. Bottom: Hourly CSF samples are processed and analyzed to determine the relative amount of labeled $A \beta$ at each hour time point. Production and clearance of $A \beta$ from the CNS are calculated during and after labeling, respectively.

onset autosomal dominant form of $\mathrm{AD}$, which comprises less than $1 \%$ of all $\mathrm{AD}$, and its direct relation to the more common later-onset form of $\mathrm{AD}$ is unclear. It has been hypothesized that the common later-onset form of AD is primarily a defect in clearance and that the rare autosomal dominant form is primarily a defect in the overproduction of $\mathrm{A} \beta_{42} \cdot{ }^{6,53-55}$ The pathology in animal models is not identical to in human disease; for example, $A \beta$ plaques in mouse models do not bind amyloid imaging agents such as $\mathrm{PiB}$ in the same way as in humans. ${ }^{26}$ This appears to be due to a basic difference in the structure of aggregated $\mathrm{A} \beta$ in mouse models. In transgenic mice, the frequency of PiB binding sites per molecule of $\mathrm{A} \beta$ is only $0.2 \%$ of the frequency in humans. ${ }^{26}$ In addition, there are recent findings indicating that the most common form of AD (i.e., with PS1 mutations) may respond differentially to $\gamma$-secretase inhibitors, ${ }^{56}$ compared with the PS1 wild type. 
3) Differences in environment may influence $\mathrm{A} \beta$ metabolism in humans, compared with animal models. Diet, ${ }^{57,58}$ medications, ${ }^{59-61}$ and environmental enrichment $^{62-65}$ have been shown to influence $A \beta$ metabolism.

4) Pharmacokinetics, the fourth category of difference between the clinical and preclinical studies, includes differences of medication compliance, administration, absorption, metabolism, excretion, and interaction with other drugs. In addition, there may be differential pharmacokinetics of the drug in the human CNS compared with the animal model CNS, due to differences in brain size, myelination, or transport mechanisms.

Because of such major differences, translation from preclinical models to clinical studies has a high rate of failure. It is therefore of critical importance that there be proper tests of the therapeutic mechanism in humans, with quantitative measurement of the therapeutic target. Proceeding forward with phase II or III studies without knowledge of whether the drug is hitting the target in humans is a potentially costly risk that may result in several years of lost progress, costs of unnecessary phase III studies, and erroneous or no conclusions at the end of clinical studies. It is critical, at early stages, to separately assess success at affecting the target and clinical response, because many pathophysiological issues remain unproven in AD. For example, it is not known for certain if clearance of $\mathrm{A} \beta$ will have a beneficial effect in mild-to-moderate AD. Therefore, full interpretation of a negative clinical study requires knowing whether or not the test drug affected brain $\mathrm{A} \beta$ but failed clinically, or whether it simply failed to have an effect on the target.

\section{Therapeutic biomarkers of $\mathbf{A} \boldsymbol{\beta}$}

For therapies that target $\mathrm{A} \beta$, recent developments have allowed for highly quantitative and informative assays of production, clearance, and aggregation of $\mathrm{A} \beta$ within the human CNS. These developments are reviewed here, as well as their potential application for measuring the effect of proposed disease-modifying therapeutics that target $\mathrm{A} \beta$. In addition to $\mathrm{A} \beta$, other important pathways in the pathophysiology of $\mathrm{AD}$ may be targeted (e.g., tau, apolipoprotein $\mathrm{E}$, or neuroinflammation). The principles discussed may be applied to those targets and other CNS targets, with the development of appropriate biomarkers.

\section{$\operatorname{Blood} \mathbf{A} \boldsymbol{\beta}$}

Amyloid- $\beta$ can be measured peripherally in the blood. ${ }^{66-68}$ Blood measurements do not correlate with central brain $\mathrm{A} \beta$ levels or with $\operatorname{CSF} \mathrm{A} \beta_{42}$ levels, as evidenced by the poor individual predictive power of blood $\mathrm{A} \beta$ levels in distinguishing elderly controls from people with $\mathrm{AD}$. This is likely due to several factors, including the very short half-life of $\mathrm{A} \beta$ in the blood compared with the central compartments and the BBB, as well as the unclear contribution of $\mathrm{CNS} A \beta$ to the blood. In $\mathrm{AD}$, there may be a disconnect between the transport mechanisms from the CNS to the blood. ${ }^{69}$

\section{CSF A $\beta$}

Levels of $A \beta$ in the CSF have been extensively tested as a diagnostic and prognostic biomarker for AD. ${ }^{40,70-73}$ CSF levels of $A \beta_{42}$ are decreased by approximately onehalf, relative to age-matched controls. There is now evidence that this decrease in $A \beta_{42}$ is indicative of CNS amyloid, as measured by PiB PET, regardless of the clinical state of the individual. ${ }^{27}$

CSF $\mathrm{A} \beta_{42}$ is an important biomarker for $\mathrm{AD}$ and has been demonstrated to be approximately $80 \%$ to $90 \%$ sensitive and specific for AD. ${ }^{27,42,74} \mathrm{~A} \beta$ levels change significantly over hours in younger normal participants, ${ }^{75}$ but this normal pattern of variation may be disrupted in age or $\mathrm{AD}$ pathology. $\mathrm{A} \beta$ dynamics are specific. Many other proteins found in the CSF do not show similar fluctuations, including apolipoprotein $\mathrm{E}$, albumin and total protein levels. ${ }^{75}$ Multiple studies have demonstrated decreased and stable $\mathrm{A} \beta_{42}$ CSF levels over time (months to years) only in patients with AD. ${ }^{76,77}$ However, one study of patients with AD showed significantly greater variability in $\mathrm{A} \beta_{40}$ levels, ${ }^{76}$ and another showed increased variability in $\mathrm{A} \beta_{1-42}$ in participants with subjective complaints ${ }^{78}$ but not in patients with dementia of the Alzheimer type. The $\mathrm{A} \beta$ dynamics in the control group may lead to an increase in false positives if a control subject's $A \beta$ levels decrease below the threshold for the diagnostic test.

The CSF is in direct communication with the extracellular space of the brain and appears to accurately reflect the levels of $A \beta$ in the brain extracellular compartment, as well as the transport of $A \beta$. The exact reason for the decrease in CSF $\mathrm{A} \beta_{42}$ while total brain $\mathrm{A} \beta_{42}$ levels are increased is still under study. One hypothesis is that the $\mathrm{A} \beta$ plaques and cerebral amyloid angiopathy within the brain act as a sink for $A \beta_{42}$, so that it cannot be transported through the extracellular fluid to the CSF and eventually to the bloodstream. ${ }^{79}$

Prior measurements of CSF A $\beta$ have been made in therapeutic trials. ${ }^{80-83}$ Some studies indicate that certain treatments can result in a decrease in detectable $\mathrm{A} \beta$, but others have not shown the predicted decrease. The choice of research participant population, sampling method, sample handling and storage, and analysis may all affect the measurements and should be accounted for in the design of studies. Because of significant fluctuation in CSF A $\beta$ levels over hours, ${ }^{75}$ there are concerns regarding the use of CSF $A \beta$ levels to measure the effects of therapeutics. In contrast to static $\mathrm{A} \beta$ levels, $\mathrm{A} \beta$ production and clearance rates determined in SILK studies do 
not have significant hourly fluctuations in the same samples. Measurements of CNS A $\beta$ kinetics in the setting of therapies that decrease $\mathrm{A} \beta$ production or increase $\mathrm{A} \beta$ clearance may provide valuable information on the pharmacodynamic effects of these therapies.

\section{Production and clearance of $\mathbf{A} \boldsymbol{\beta}$}

The SILK methodology can be used to determine the effect of a drug on production, clearance, or the CNS soluble pool of $\mathrm{A} \beta$. A recently completed study using a $\gamma$-secretase inhibitor suggests that measurement of newly generated $\mathrm{A} \beta$ in the CSF can demonstrate a significant dose-response relationship with five subjects in each group (unpublished data [in preparation]). Studies may be designed to measure the production and clearance of $\mathrm{A} \beta$ between groups. Results of a drug effect in humans may be obtained in an acute dose study, obviating the need for chronic administration studies to determine proof of action of the therapy. $\beta$-Secretase and $\gamma$-secretase inhibitors, which have the potential to decrease newly generated CNS A $\beta$, can be tested and their effects quantified in placebo-controlled studies using SILK. Similarly, $\mathrm{A} \beta$ clearance can be measured with a putative clearance-enhancing drug. Increased clearance of soluble $\mathrm{A} \beta$ caused by transport out of the CNS or breakdown within the CNS will be manifested as a decreased clearance rate in a CNS SILK study.

\section{CNS amyloid imaging}

To date, nine amyloid imaging agents have been tried in human studies. ${ }^{84-92}$ Of these, only PiB and FDDNP have undergone extensive evaluation in $\mathrm{AD}$ and mild cognitive impairment (MCI). All of these agents appear to target fibrillary $\mathrm{A} \beta$ deposits, presumably because these agents have been derived from histological dyes specific for $\beta$-sheet amyloid deposits. In the context of $\mathrm{AD}$, these agents primarily reflect $\mathrm{A} \beta$ in plaques and cerebrovascular amyloid. When tangles and plaques coexist, it would be difficult to detect a tangle-specific signal, due to the signal from the much larger $\mathrm{A} \beta$ pool. However, when tangles are present in isolation (e.g., in tauopathies), it is conceivable that amyloid imaging could detect a tangle-specific signal. Nonetheless, there is no direct evidence of detection of an in vivo signal from tangles with any existing imaging agent.

These agents have demonstrated the presence of $\mathrm{A} \beta$ deposits in the vast majority of clinically diagnosed $\mathrm{AD}$ patients, $50 \%$ to $75 \%$ of MCI patients and in $20 \%$ to $30 \%$ of cognitively normal elderly. Good correlation of in vivo retention with postmortem levels of $\mathrm{A} \beta$ has been demonstrated for $\mathrm{PiB}^{50}$ The test-retest variability of $\mathrm{PiB}$ PET is on the order of $5 \%$ to $8 \%$, being lowest in areas with high PiB retention. ${ }^{86,93}$ Plaque load appears to plateau by the mild stage of clinical AD. ${ }^{94}$ The implications of this for monitoring of therapy is that, for a meaningful effect of a drug to be detected in $\mathrm{AD}$ with amyloid imaging, the drug should decrease the load of deposited $\mathrm{A} \beta$ by at least $15 \%$. This effect would seem biologically meaningful (i.e., a signal that is two to three times the noise inherent in the measurement). From a statistical viewpoint, a decrease in $\mathrm{PiB}$ retention of $15 \%$ should give greater than $90 \%$ power for detecting a significant effect in a typical sample of AD patients with no more than 20 subjects.

Decreasing production or decreasing the soluble pool of $\mathrm{A} \beta$ may not be detectable - at least not acutelyunless the treatment ultimately shifts the equilibrium away from the deposited form of $\mathrm{A} \beta$. Amyloid imaging may be best suited for therapy-monitoring of drugs intended to increase clearance in the setting of $\mathrm{AD}$, and perhaps of MCI (e.g., immunotherapy). If presymptomatic or preventive treatment trials are begun in individuals who show early amyloid deposition, then it may be possible to detect the effect of drugs that slow $\mathrm{A} \beta$ deposition, because this is the most active phase of $\mathrm{A} \beta$ accumulation. Another use of amyloid imaging in therapeutic studies is to screen-in only subjects who have significant $\mathrm{A} \beta$ deposition, because it would make little sense to include a subject with no brain $\mathrm{A} \beta$ deposits in a clinical trial of an antiamyloid drug.

\section{Downstream biomarkers}

Measurements of biomarkers downstream of the target may be performed including structural MRI of the brain, electroencephalograms, magnetoencephalograms, inflammatory biomarkers, or other biomarkers not directly tied to the mechanism of action. The interpretation of these downstream biomarkers may assist in determining secondary effects, but do not inform on the treatment mechanism of action. For example, in the AN 1792 trial, $\mathrm{A} \beta$ immunization was associated with a paradoxical shrinkage of brain as measured by MRI. ${ }^{95}$ The predicted response was slowing of atrophy due to beneficial effect of the immunization. MRI results of increased or decreased shrinkage have both been interpreted as potentially beneficial.

\section{ADDITIONAL TREATMENT APPROACHES TO A $\beta$ MODULATION}

Other approaches to altering $\mathrm{A} \beta$ metabolism are discussed elsewhere in this issue, including RAGE inhibitors [Zlokovic, ${ }^{96}$ this issue], and direct plaque inhibitors [Landreth et al, ${ }^{97}$ this issue]. These may be measured by their respective pharmacodynamic activity directly in CNS system by sampling of CSF, or imaging.

\section{Pharmacodynamic effect confirmation in humans}

The results of a therapeutic biomarker study can be used to design and interpret a phase III clinical outcomes study. Specifically, evidence of a pharmacodynamic effect in the patient population of interest and possible 
clinical effects are important to consider in future phase III trials. For example, if a phase II study drug results in no significant clinical change and no change in the target of that drug in the patient population, it is unlikely to have a significant effect on the course of disease in a phase III study. However, if a phase II study shows evidence of therapeutic target effect without a significant clinical benefit in a short phase II trial, it is still possible that the treatment will produce a significant clinical benefit in a phase III trial. If in a phase II study it is found that the treatment significantly affects both the pharmacodynamic measurement and clinical outcomes, it is likely that the phase III study will confirm this in a larger population set and help validate the pharmacodynamic biomarker as a potential surrogate biomarker that can be used in the future refinement of the proposed therapy, as well as other therapies. A phase III study can be designed to maximize the chances of determining clinical benefit by determining the effective route, dosage, and timing of the therapy by incorporating information on the treatment effect on the target and comparison of dose escalation from phase II studies.

\section{Defining the therapeutic window of $A \beta$ modulation}

It is not known to what degree $\mathrm{A} \beta$ metabolism needs to be modulated to have clinical benefit. For example, recent studies with $\gamma$-secretase inhibitors in mouse models indicate that a $30 \%$ to $50 \%$ decrease of $\gamma$-secretase activity decreases the formation of amyloid pathology in mice when this decrease in $\gamma$-secretase activity is maintained for the life of the mouse. ${ }^{98}$ Once $\mathrm{A} \beta$ deposits are present, however, decreasing $\mathrm{A} \beta$ production by $95 \%$ in an animal model did not reverse established pathologybut it did prevent further worsening of the amyloid plaque load. ${ }^{99}$ An unresolved question is what degree of $\beta$-secretase or $\gamma$-secretase inhibition, if any, is necessary to improve the clinical outcomes of AD. In addition, the timing of treatment during the disease process may be a critical factor.

Ultimately, the clinical outcome is the most important parameter to patients, family members, clinicians, and regulatory agencies. Therefore, any degree of pharmacodynamic modulation in $A \beta$ or other pathways must ultimately be tied directly to the clinical outcomes. With this knowledge, future therapeutic approaches and refinements can target the appropriate level of $\mathrm{A} \beta$ inhibition or clearance to maximize therapeutic efficacy while limiting toxicity. Measurements of therapeutic effects on molecular targets in phase II studies may include amyloid imaging by $\mathrm{PiB} \mathrm{PET}^{100}$ or another molecular imaging agent. It also may include other biomarkers specific for pharmacodynamic assessment, including the production and clearance rates of $\mathrm{A} \beta$, as well as estimates of $\mathrm{A} \beta$ pool size in the central nervous system. It may also include enzyme-linked immunosorbent assay measure- ments of CSF and plasma $A \beta$ for estimates of activity in the central and peripheral compartments and correlation to production and clearance rates.

\section{Phase III confirmation of pharmacodynamic effect}

In phase III studies, the effect of pharmacodynamic measurements should be correlated with clinical outcomes. For example, induction of anti-A $\beta$ plaque antibodies by patients in the AN-1792 active vaccination trial was correlated with slowed cognitive decline. ${ }^{101}$ Direct measurements of CSF A $\beta$ concentration levels, production, clearance, or amyloid imaging, may provide evidence for successful modulation of the therapeutic target. The amount of target effect can be correlated with clinical changes, supporting development of a treatment biomarker. In addition, measurement of downstream biomarkers with electroencephalography, MRI, and cognitive and clinical testing can be performed to determine effects on atrophy, electrical activity, and cognitive performance. Such testing allows for confirmation that the drug is hitting its target and quantitates to what degree. The results of a phase III study can provide significant data to assist in the design of future treatment studies. Without the measurement of the target of the drug in phase II and phase III studies, an uninformative study may result. This may result in the loss of several years of work, with no interpretable data to advance further studies for the development of future drugs.

\section{Logic of testing pharmacodynamic effect in phase III}

In a negative phase III trial, for example, any of four conditions may exist:

1) The drug is not hitting its target, and therefore produces no effect (i.e., ineffective drug).

2) The drug was hitting its target but at a level lower than needed to have a clinical effect (i.e., insufficient potency or dose).

3) The drug was hitting its target at a level predicted to have a clinical effect, but there still was no clinical effect (i.e., incorrect target).

4) The drug was hitting its target and having a beneficial clinical effect; however, because of study design, adverse events, or serious side effectsissues not specific to the target-these benefits were not observed (i.e., confounding effects in the study).

Without information regarding a target effect, one can not distinguish among these possibilities.

\section{Refining the treatment}

One can conclude whether a given level of target modulation is sufficient to modulate the clinical disease by measuring the clinical and pharmacodynamic effects in 
patients. For example, if $15 \%$ inhibition of $\mathrm{A} \beta$ production with a secretase inhibitor is achieved but there is no change in clinical progression, then one can conclude that future therapies need to inhibit more than $15 \%$ to have a reasonable chance of benefit. Only from welldesigned trials, regardless of whether they are clinically positive or negative, will understanding of $\mathrm{AD}$ treatment grow to the point where highly effective treatments for $\mathrm{AD}$ are likely to be refined. As a case in point, extensive development in the cardiovascular field has occurred by having a surrogate biomarker such as LDL cholesterol level to predict the response to treatment. This has led to rapid development of drugs which treat hypercholesterolemia and lower the risk of heart attacks and strokes.

To summarize, measuring the therapeutic effect of therapies directly in humans can provide answers to the following questions:

1) Is the treatment hitting its target of amyloid plaques, $\mathrm{A} \beta$ production, $\mathrm{A} \beta$ clearance, $\mathrm{A} \beta \mathrm{CNS}$ levels, tau, phospho-tau, or other biomolecules involved with disease pathogenesis?

2) What is the duration and magnitude of the drug effect? (This will allow for deciding dose selection and frequency of medication.)

3) How much soluble or insoluble $A \beta$ modulation is needed for a positive clinical outcome? Is more better? Do certain patients respond more favorably than others?

4) What form of $A \beta$ is it critical to affect: soluble $A \beta$, oligomeric $A \beta$ species, insoluble amyloid plaques or some combination of these? For example, if therapies that primarily target one form of $\mathrm{A} \beta$ appear to be clinically beneficial but therapies that target other forms do not, this would provide strong evidence regarding which is the more toxic species.

5) What species of $\mathrm{A} \beta\left(\mathrm{A} \beta_{42}, \mathrm{~A} \beta_{40}\right.$, or others) are the best targets of therapeutic intervention?

These questions can be answered with well-designed studies using direct measurements of drug targets in human studies throughout all phases of clinical drug testing.

\section{REFERENCES}

1. Hebert LE, Scherr PA, Bienias JL, Bennett DA, Evans DA. Alzheimer disease in the US population: prevalence estimates using the 2000 census. Arch Neurol 2003;60:1119-1122.

2. Selkoe DJ. Alzheimer disease: mechanistic understanding predicts novel therapies. Ann Intern Med 2004;140:627-638.

3. Glenner GG, Wong CW. Alzheimer's disease: initial report of the purification and characterization of a novel cerebrovascular amyloid protein. Biochem Biophys Res Commun 1984;120:885-890.

4. Rovelet-Lecrux A, Hannequin D, Raux G, et al. APP locus duplication causes autosomal dominant early-onset Alzheimer disease with cerebral amyloid angiopathy. Nat Genet 2006;38:2426.
5. Goate A, Chartier-Harlon MC, Mullan M, et al. Segregation of a missense mutation in the amyloid precursor protein gene with familial Alzheimer's disease. Nature 1991;349:704-706.

6. Kumar-Singh S, Theuns J, Van Broeck B, et al. Mean age-ofonset of familial Alzheimer disease caused by presenilin mutations correlates with both increased $\mathrm{A} \beta 42$ and decreased $\mathrm{A} \beta 40$. Hum Mutat 2006;27:686-695.

7. Sleegers K, Brouwers N, Gijselinck I, et al. APP duplication is sufficient to cause early onset Alzheimer's dementia with cerebral amyloid angiopathy. Brain 2006;129:2977-2983.

8. Games D, Buttini M, Kobayashi D, Schenk D, Seubert P. Mice as models: transgenic approaches and Alzheimer's disease. J Alzheimers Dis 2006;9:133-149.

9. Spires TL, Hyman BT. Transgenic models of Alzheimer's disease: learning from animals. NeuroRx 2005;2:423-437.

10. Andorfer C, Kress Y, Espinoza M, et al. Hyperphosphorylation and aggregation of tau in mice expressing normal human tau isoforms. J Neurochem 2003;86:582-590.

11. Oddo S, Caccamo A, Shepherd JD, et al. Triple-transgenic model of Alzheimer's disease with plaques and tangles: intracellular A $\beta$ and synaptic dysfunction. Neuron 2003;39:409-421.

12. Van Dooren T, Muyllaert D, Borghgraef P, et al. Neuronal or glial expression of human apolipoprotein E4 affects parenchymal and vascular amyloid pathology differentially in different brain regions of double- and triple-transgenic mice. Am J Pathol 2006; 168:245-260.

13. Duyckaerts C, Potier MC, Delatour B. Alzheimer disease models and human neuropathology: similarities and differences. Acta Neuropathol 2008;115:5-38.

14. McLean CA, Cherny RA, Fraser FW, et al. Soluble pool of A $\beta$ amyloid as a determinant of severity of neurodegeneration in Alzheimer's disease. Ann Neurol 1999;46:860-866.

15. Goedert M, Spillantini MG. A century of Alzheimer's disease. Science 2006;314:777-781.

16. Necula M, Kayed R, Milton S, Glabe CG. Small molecule inhibitors of aggregation indicate that amyloid $\beta$ oligomerization and fibrillization pathways are independent and distinct. J Biol Chem 2007;282:10311-10324.

17. Lacor PN, Buniel MC, Furlow PW, et al. A $\beta$ Oligomer-induced aberrations in synapse composition, shape, and density provide a molecular basis for loss of connectivity in Alzheimer's disease. J Neurosci 2007;27:796-807.

18. Walsh DM, Selkoe DJ. A $\beta$ oligomers: a decade of discovery. J Neurochem 2007;101:1172-1184.

19. Haass C, Selkoe DJ. Soluble protein oligomers in neurodegeneration: lessons from the Alzheimer's amyloid $\beta$-peptide. Nat Rev Mol Cel Biol 2007;8:101-112.

20. Masliah E, Sisk A, Mallory M, Mucke L, Schenk D, Games D. Comparison of neurodegenerative pathology in transgenic mice overexpressing V717F $\beta$-amyloid precursor protein and Alzheimer's disease. J Neurosci 1996;16:5795-5811.

21. Cras P, Kawai M, Lowery D, Gonzalez-DeWhitt P, Greenberg B, Perry G. Senile plaque neurites in Alzheimer disease accumulate amyloid precursor protein. Proc Natl Acad Sci U S A 1991;88: $7552-7556$.

22. Masliah E, Mallory M, Deerinck T, et al. Re-evaluation of the structural organization of neuritic plaques in Alzheimer's disease. J Neuropathol Exp Neurol 1993;52:619-632.

23. Cleary JP, Walsh DM, Hofmeister JJ, et al. Natural oligomers of the amyloid- $\beta$ protein specifically disrupt cognitive function. Nat Neurosci 2005;8:79-84.

24. Walsh DM, Klyubin I, Fadeeva JV, et al. Naturally secreted oligomers of amyloid $\beta$ protein potently inhibit hippocampal long-term potentiation in vivo. Nature 2002;416:535-539.

25. Klunk WE, Engler H, Nordberg A, et al. Imaging brain amyloid in Alzheimer's disease with Pittsburgh Compound-B. Ann Neurol 2004;55:306-319.

26. Klunk WE, Lopresti BJ, Ikonomovic MD, et al. Binding of the positron emission tomography tracer Pittsburgh Compound-B reflects the amount of amyloid- $\beta$ in Alzheimer's disease brain but not in transgenic mouse brain. J Neurosci 2005;25:10598-10606. 
27. Fagan AM, Mintun MA, Mach RH, et al. Inverse relation between in vivo amyloid imaging load and cerebrospinal fluid $\mathrm{A} \beta_{42}$ in humans. Ann Neurol 2006;59:512-519.

28. Masters CL, Cappai R, Barnham KJ, Villemagne VL. Molecular mechanisms for Alzheimer's disease: implications for neuroimaging and therapeutics. J Neurochem 2006;97:1700-1725.

29. Jacobsen JS, Reinhart P, Pangalos MN. Current concepts in therapeutic strategies targeting cognitive decline and disease modification in Alzheimer's disease. NeuroRx 2005;2:612-626.

30. Vassar R, Bennett BD, Babu-Khan S, et al. $\beta$-Secretase cleavage of Alzheimer's amyloid precursor protein by the transmembrane aspartic protease BACE. Science 1999;286:735-741.

31. Buckner RL, Snyder AZ, Shannon BJ, et al. Molecular, structural, and functional characterization of Alzheimer's disease: evidence for a relationship between default activity, amyloid, and memory. J Neurosci 2005;25:7709-7717.

32. Kang JE, Cirrito JR, Dong H, Csernansky JG, Holtzman DM. Acute stress increases interstitial fluid amyloid- $\beta$ via corticotropin-releasing factor and neuronal activity. Proc Natl Acad Sci U S A 2007;104:10673-10678.

33. Cirrito JR, Yamada KA, Finn MB, et al. Synaptic activity regulates interstitial fluid amyloid- $\beta$ levels in vivo. Neuron $2005 ; 48$ : 913-922.

34. Fukumoto H, Cheung BS, Hyman BT, Irizarry MC. $\beta$-Secretase protein and activity are increased in the neocortex in Alzheimer disease. Arch Neurol 2002;59:1381-1389.

35. Holtzman DM. Amyloid- $\beta$ binding molecule: potential role in the pathogenesis and treatment of Alzheimer disease. Alzheimer Dis Assoc Disord 2003;17 Suppl 2:S66-S68.

36. Lippa CF, Saunders AM, Smith TW, et al. Familial and sporadic Alzheimer's disease: neuropathology cannot exclude a final common pathway. Neurology 1996;96:406-412.

37. Klunk WE, Price JC, Mathis CA, et al. Amyloid deposition begins in the striatum of presenilin-1 mutation carriers from two unrelated pedigrees. J Neurosci 2007;27:6174-6184.

38. Games D, Adams D, Alessandrini R, et al. Alzheimer-type neuropathology in transgenic mice overexpressing V717F $\beta$-amyloid precursor protein. Nature 1995;373:523-527.

39. Cirrito JR, May PC, O'Dell MA, et al. In vivo assessment of brain interstitial fluid with microdialysis reveals plaque-associated changes in amyloid- $\beta$ metabolism and half-life. J Neurosci 2003; 23:8844-8853.

40. Sunderland T, Linker G, Mirza N, et al. Decreased $\beta$-amyloid ${ }_{1-42}$ and increased tau levels in cerebrospinal fluid of patients with Alzheimer's disease [Erratum in: JAMA 2007;298:1516]. JAMA 2003;289:2094-2103.

41. Clark CM, Xie S, Chittams J, et al. Cerebrospinal fluid tau and $\beta$-amyloid: how well do these biomarkers reflect autopsy-confirmed dementia diagnoses? Arch Neurol 2003;60:1696-1702.

42. Galasko D, Chang L, Motter R, et al. High cerebrospinal fluid tau and low amyloid $\beta 42$ levels in the clinical diagnosis of Alzheimer disease and relation to apolipoprotein E genotype. Arch Neurol 1998;55:937-945.

43. Mayeux R, Honig LS, Tang MX, et al. Plasma A $\beta 40$ and $A \beta 42$ and Alzheimer's disease: relation to age, mortality, and risk. Neurology 2003;61:1185-1190.

44. Bateman RJ, Munsell LY, Chen X, Holtzman DM, Yarasheski KE. Stable isotope labeling tandem mass spectrometry (SILT) to quantify protein production and clearance rates. J Am Soc Mass Spectrom 2007;18:997-1006.

45. Bateman RJ, Munsell LY, Morris JC, Swarm R, Yarasheski KE, Holtzman DM. Human amyloid- $\beta$ synthesis and clearance rates as measured in cerebrospinal fluid in vivo. Nat Med 2006;12: $856-861$.

46. Younkin SG. The APP and PS1/2 mutations linked to early onset familial Alzheimer's disease increase the extracellular concentration and A $\beta 1-42$ (43). Rinsho Shinkeigaku 1997;37:1099. (abstract)

47. Meyer-Luehmann M, Spires-Jones TL, Prada C, et al. Rapid appearance and local toxicity of amyloid- $\beta$ plaques in a mouse model of Alzheimer's disease. Nature 2008;451:720-724.

48. Dickson TC, Vickers JC. The morphological phenotype of $\beta$-amyloid plaques and associated neuritic changes in Alzheimer's disease. Neuroscience 2001;105:99-107.
49. Bacskai BJ, Frosch MP, Freeman SH, et al. Molecular imaging with Pittsburgh compound B confirmed at autopsy: a case report. Arch Neurol 2007;64:431-434.

50. Ikonomovic MD, Klunk WE, Abrahamson EE, et al. Post-mortem correlates of in vivo PiB-PET amyloid imaging in a typical case of Alzheimer's disease. Brain 2008 Mar 12. Epub ahead of print

51. Fodero-Tavoletti MT, Smith DP, McLean CA, et al. In vitro characterization of Pittsburgh compound-B binding to Lewy bodies. J Neurosci 2007;27:10365-10371.

52. Lehman EJH, Kulnane LS, Gao Y, et al. Genetic background regulates $\beta$-amyloid precursor protein processing and $\beta$-amyloid deposition in the mouse. Hum Mol Genet 2003;12:2949-2956.

53. Scheuner D, Eckman C, Jensen M, et al. Secreted amyloid $\beta$-protein similar to that in the senile plaques of Alzheimer's disease is increased in vivo by the presenilin 1 and 2 and APP mutations linked to familial Alzheimer's disease. Nat Med $1996 ; 2: 864-870$

54. Lemere CA, Lopera F, Kosik KS, et al. The E280A presenilin 1 Alzheimer mutation produces increased $\mathrm{A} \beta 42$ deposition and severe cerebellar pathology. Nat Med 1996;2:1146-1150.

55. Golde TE, Cai XD, Shoji M, Younkin SG. Production of amyloid beta protein from normal amyloid beta-protein precursor (beta APP) and the mutated beta APPs linked to familial Alzheimer's disease. Ann N Y Acad Sci 1993;695:103-108.

56. Czirr E, Leuchtenberger S, Dorner-Ciossek C, et al. Insensitivity to A $\beta 42$-lowering nonsteroidal anti-inflammatory drugs and $\gamma$-secretase inhibitors is common among aggressive presenilin-1 mutations. J Biol Chem 2007;282:24504-24513.

57. Luchsinger JA, Mayeux, R. Dietary factors and Alzheimer's disease. Lancet Neurol 2004;3:579-587.

58. Halagappa VKM, Guo Z, Pearson M, et al. Intermittent fasting and caloric restriction ameliorate age-related behavioral deficits in the triple-transgenic mouse model of Alzheimer's disease. Neurobiol Dis 2007;26:212-220.

59. Eriksen JL, Sagi SA, Smith TE, et al. NSAIDs and enantiomers of flurbiprofen target $\gamma$-secretase and lower $\mathrm{A} \beta 42$ in vivo. J Clin Invest 2003;112:440-449.

60. Kukar T, Murphy MP, Eriksen JL, et al. Diverse compounds mimic Alzheimer disease-causing mutations by augmenting A $\beta 42$ production. Nat Med 2005;11:545-550.

61. Weggen S, Eriksen JL, Sagi SA, et al. Evidence that nonsteroidal anti-inflammatory drugs decrease amyloid $\beta 42$ production by direct modulation of $\gamma$-secretase activity. J Biol Chem 2003;278: 31831-31837.

62. Berardi N, Braschi C, Capsoni S, Cattaneo A, Maffei L. Environmental enrichment delays the onset of memory deficits and reduces neuropathological hallmarks in a mouse model of Alzheimer-like neurodegeneration. J Alzheimers Dis 2007;11:359-370.

63. Cracchiolo JR, Mori T, Nazian SJ, Tan J, Potter H, Arendash GW. Enhanced cognitive activity-over and above social or physical activity - is required to protect Alzheimer's mice against cognitive impairment, reduce $\mathrm{A} \beta$ deposition, and increase synaptic immunoreactivity. Neurobiol Learn Mem 2007;88:277-294.

64. Jankowsky JL, Xu G, Fromholt D, Gonzales V, Borchelt DR. Environmental enrichment exacerbates amyloid plaque formation in a transgenic mouse model of Alzheimer disease. J Neuropathol Exp Neurol 2003;62:1220-1227.

65. Lazarov O, Robinson J, Tang YP, et al. Environmental enrichment reduces $\mathrm{A} \beta$ levels and amyloid deposition in transgenic mice. Cell 2005;120:701-713.

66. Podlisny MB, Mammen AL, Schlossmacher MG, Palmert MR, Younkin SG, Selkoe DJ. Detection of soluble forms of the $\beta$-amyloid precursor protein in human plasma. Biochem Biophys Res Commun 1990;167:1094-1101.

67. Fukumoto H, Tennis M, Locascio JJ, et al. Age but not diagnosis is the main predictor of plasma amyloid $\beta$-protein levels. Arch Neurol 2003;60:958-964.

68. Graff-Radford NR, Crook JE, Lucas J, et al. Association of low plasma $\mathrm{A} \beta 42 / \mathrm{A} \beta 40$ ratios with increased imminent risk for mild cognitive impairment and Alzheimer disease [Erratum in: Arch Neurol 2007;64:1246]. Arch Neurol 2007;64:354-362.

69. Deane R, Zlokovic BV. Role of the blood-brain barrier in the 
pathogenesis of Alzheimer's disease. Curr Alzheimer Res 2007;4:191-197.

70. Bibl M, Mollenhauer B, Esselmann H, et al. CSF amyloid- $\beta$ peptides in Alzheimer's disease, dementia with Lewy bodies and Parkinson's disease dementia. Brain 2006;129:1177-1187.

71. De Jong D, Jansen RWMM, Kremer BPH, Verbeek MM. Cerebrospinal fluid amyloid $\beta_{42} /$ phosphorylated tau ratio discriminates between Alzheimer's disease and vascular dementia. J Gerontol A Biol Sci Med Sci 2006;61:755-758.

72. Fagan AM, Roe CM, Xiong C, Mintun MA, Morris JC, Holtzman DM. Cerebrospinal fluid tau/ $\beta$-amyloid42 ratio as a prediction of cognitive decline in nondemented older adults. Arch Neurol 2007;64:343-349.

73. Hampel H, Teipel SJ, Fuchsberger T, et al. Value of CSF $\beta$-amyloid $_{1-42}$ and tau as predictors of Alzheimer's disease in patients with mild cognitive impairment. Mol Psychiatry 2004;9:705-710.

74. Hansson O, Zetterberg H, Buchhave P, Londos E, Blennow K, Minthon L. Association between CSF biomarkers and incipient Alzheimer's disease in patients with mild cognitive impairment: a follow-up study [Erratum in: Lancet Neurol 2006;5:293]. Lancet Neurol 2006;5:228-234.

75. Bateman RJ, Wen G, Morris JC, Holtzman DM. Fluctuations of CSF amyloid- $\beta$ levels: implications for a diagnostic and therapeutic biomarker. Neurology 2007;68:666-669.

76. Kanai M, Matsubara E, Isoe $\mathrm{K}$, et al. Longitudinal study of cerebrospinal fluid levels of tau, $\mathrm{A} \beta 1-40$, and $\mathrm{A} \beta 1-42(43)$ in Alzheimer's disease: a study in Japan. Ann Neurol 1998;44:1726.

77. Andreasen N, Hesse C, Davidsson P, et al. Cerebrospinal fluid $\beta$ - amyloid $_{1-42}$ in Alzheimer's disease: differences between earlyand late-onset Alzheimer's disease and stability during the course of disease. Arch Neurol 1999;56:673-680.

78. Bouwman FH, Van Der Flier WM, Schoonenboom NSM, et al. Longitudinal changes of CSF biomarkers in memory clinic patients. Neurology 2007;69:1006-1011.

79. DeMattos RB, Bales KR, Parsadanian M, et al. Plaque-associated disruption of CSF and plasma amyloid- $\beta(\mathrm{A} \beta)$ equilibrium in a mouse model of Alzheimer's disease. J Neurochem 2002;81: 229-236.

80. Nitsch RM, Deng M, Tennis M, Schoenfeld D, Growdon JH. The selective muscarinic M1 agonist AF102B decreases levels of total $\mathrm{A} \beta$ in cerebrospinal fluid of patients with Alzheimer's disease. Ann Neurol 2000;48:913-918.

81. Tokuda T, Oide T, Tamaoka A, Ishii K, Matsuno S, Ikeda S. Prednisolone (30-60 mg/day) for diseases other than AD decreases amyloid $\beta$-peptides in CSF. Neurology 2002;58:14151418.

82. Aisen PS, Saumier D, Briand R, et al. A phase II study targeting amyloid- $\beta$ with 3 APS in mild-to-moderate Alzheimer disease. Neurology 2006;67:1757-1763.

83. Siemers ER, Quinn JF, Kaye J, et al. Effects of a $\gamma$-secretase inhibitor in a randomized study of patients with Alzheimer disease. Neurology 2006;66:602-604.

84. Friedland RP, Kalaria R, Berridge M, et al. Neuroimaging of vessel amyloid in Alzheimer's disease. Ann N Y Acad Sci 1997;826:242-247.

85. Small GW, Kepe V, Ercoli LM, et al. PET of brain amyloid and tau in mild cognitive impairment. N Engl J Med 2006;355:26522663.

86. Lopresti BJ, Klunk WE, Mathis CA, et al. Simplified quantification of Pittsburgh compound B amyloid imaging PET studies: a comparative analysis. J Nucl Med 2005;46:1959-1972.

87. Verhoeff NP, Wilson AA, Takeshita S, et al. In-vivo imaging of Alzheimer disease $\beta$-amyloid with $\left[{ }^{11} \mathrm{C}\right] \mathrm{SB}-13$ PET. Am J Geriatr Psychiatry 2004;12:584-595.

88. Opazo C, Luza S, Villemagne VL, et al. Radioiodinated clioquinol as a biomarker for $\beta$-amyloid: Zn complexes in Alzheimer's disease. Aging Cell 2006;5:69-79.

89. Kudo Y, Okamura N, Furumoto S, et al. 2-(2-[2-Dimethylaminothiazol-5-yl]ethenyl)-6-(2-[fluoro]ethoxy)benzoxazole: a novel PET agent for in vivo detection of dense amyloid plaques in Alzheimer's disease patients. J Nucl Med 2007;48:553-5611.

90. Seibyl J, Jennings D, Koren A, et al. Clinical evaluation of 123-I IMPY as a $\beta$-amyloid imaging biomarker in Alzheimer's subjects and controls. J Nucl Med 2007;48 Suppl 2:57P (abstract).

91. Rowe CC, Ackerman U, Browne W, et al. Imaging of amyloid $\beta$ in Alzheimer's disease with ${ }^{18} \mathrm{~F}-\mathrm{BAY} 94-9172$, a novel PET tracer: proof of mechanism. Lancet Neurol 2008;7:129-135.

92. Mathis CA, Lopresti B, Mason N, et al. Comparison of the amyloid imaging agents [F-18] $3^{\prime}$-F-PIB and [C-11]PIB in Alzheimer's disease and control subjects. J Nucl Med 2007;48 Suppl 2:56P (abstract).

93. Price JC, Klunk WE, Lopresti BJ, et al. Kinetic modeling of amyloid binding in humans using PET imaging and Pittsburgh compound-B. J Cereb Blood Flow Metab 2005;25:1528-1547.

94. Engler H, Forsberg A, Almkvist O, et al. Two-year follow-up of amyloid deposition in patients with Alzheimer's disease. Brain 2006;129:2856-2866.

95. Fox NC, Black RS, Gilman S, et al. Effects of Abeta immunization (AN1792) on MRI measures of cerebral volume in Alzheimer disease. Neurology 2005;64:1563-1572.

96. Zlokovic BV. New therapeutic targets in the neurovascular pathway in Alzheimer's disease. Neurotherapeutics 2008;5:409-414.

97. Landreth G, Jiang Q, Mandrekar S, Heneka M. PPAR $\gamma$ agonists as therapeutics for the treatment of Alzheimer's disease. Neurotherapeutics 2008;5:481-489.

98. Li T, Wen H, Brayton C, et al. Moderate reduction of $\gamma$-secretase attenuates amyloid burden and limits mechanism-based liabilities. J Neurosci 2007;27:10849-10859.

99. Jankowsky JL, Slunt HH, Gonzales V, et al. Persistent amyloidosis following suppression of $\mathrm{A} \beta$ production in a transgenic model of Alzheimer disease. PLoS Med 2005;2:1318-1333(e355).

100. Mathis CA, Lopresti BJ, Klunk WE. Impact of amyloid imaging on drug development in Alzheimer's disease. Nucl Med Biol 2007;34:809-822.

101. Hock C, Konietzko U, Streffer JR, et al. Antibodies against $\beta$-amyloid slow cognitive decline in Alzheimer's disease. Neuron 2003;38:547-554. 